Aqdas Ali Kazmi 75

\title{
Ricardian Equivalence Hypothesis: Some Empirical Tests for Pakistan Based on Blanchard-Evans Models
}

\section{Aqdas Ali Kazmi ${ }^{1}$}

During the last three decades, the Ricardian Equivalence Hypothesis (REH) has been an important theme of economic research both theoretical and applied in the industrial countries especially the US. However, very limited work has been done in the developing countries to test the validity and consistency of this hypothesis. In this paper an attempt has been made to present some empirical tests of the hypothesis for Pakistan using the macroeconomic data for the period 1960-88 based on the standard Blanchard-Evans Models of intertemporal allocation of resources as affected by the perceptions of the consumers about debt accumulation. The paper has been divided into three parts. In part-I, a brief introduction to the Ricardian Equivalence Hypothesis as well its origins has been delineated. In part-II, the Blanchard (1985) Model has been outlined along with the testable hypotheses as derived by Evans (1988). Part-III summarily presents the results of the Blanchard-Evans Models as applied to Pakistan data. These results fail to validate the Ricardian Equivalence Hypotheses for Pakistan. However the results are sensitive to the manner in which the critical variable namely "wealth" is defined and the manner in which the models are estimated. Therefore, further research is required on the subject especially in the contest of Pakistan's economy which has accumulated large public debt so as to analyse precisely the extent to which public debt is discounted by the consumers as future tax liabilities.

\section{Part-I}

\section{Ricardian Equivalence Hypothesis}

The Ricardian Equivalence Hypothesis (REH) postulates that under certain circumstances and for a given path of expenditures, the substitution of debt for taxes does not affect private sector wealth and consumption. This hypothesis is based on the premise that debt financing is only a change in the timing of taxation that has no impact on private consumption if the present value of the stream of taxation remains unchanged. Since REH has far reaching implications for the efficacy of fiscal policy in demand

\footnotetext{
${ }^{1}$ The author is Joint Chief Economist (Operations), Planning Commission, Islamabad.
} 
management of an economy, it has been a subject of extensive theoretical and empirical research in the industrial countries, especially the U.S. However, very limited work has been undertaken in the developing countries to test the validity of this important hypothesis of public finance.

The fundamental logic underlying this hypothesis of debt neutrality was originally presented by David Ricardo (Sraffa, 1951) in Chapter XVII entitled: "Taxes on Other Commodities than Raw Produce" of his celebrated "The Principles of Political Economy and Taxation". Although Ricardo explained why government debt and taxes could be equivalent, he never sponsored the case for unlimited issue of government bonds. In fact, he warned against the consequences of continuous fiscal deficits in the following words: "From what I have said, it must not be inferred that I consider the system of borrowing as the best calculated to defray the extraordinary expenses of the state. It is a system which tends to make us less thrifty to blind us to our real situation."

The question of debt vs. taxes has important repercussions for the theory dealing with national income determination. In this theory, the aggregate consumption function plays a fundamental role, because aggregate consumption is often specified to depend on contemporaneous aggregate disposable income and on aggregate wealth. The question is whether the public's holding of bonds issued by the government should be treated as part of aggregate wealth. If consumers recognise that these bonds, in aggregate, represent future tax liabilities, then these bonds would not be part of aggregate wealth. If, on the other hand, consumers do not recognise or for some reason do not care about the implied future tax liabilities associated with these bonds, they should be counted as part of aggregate wealth in an aggregate consumption function. This question was recognised by Patinkin (1965) and he specified that a fraction $\mathrm{k}$ of the stock of outstanding government bonds is to be treated as wealth. Under the RE view, $\mathrm{k}$ would be equal to zero; under the view that consumers ignore future tax liabilities, $\mathrm{k}$ would be equal to one. Bailey (1971) also dealt with the question of whether future tax liabilities affect aggregate consumption in a model of national income determination, though his formulation of the aggregate consumption function does not explicitly include aggregate wealth. Despite this limitation, Bailey's model is one of the earliest attempts which recognise the role of public bonds in consumption and income determination.

The current debate on REH has its roots in a seminal paper by Barro (1974). In an overlapping generation model in which individuals have an infinite life span but altruistic bequest motives, Barro shows that if there 
exists a chain of effective transfers between generations, there cannot be any net-wealth effects on aggregate demand. Formally an individual of generation $i$ maximises

$$
\text { Ui (Ciy, Cio, U*i +1) }
$$

subject to a first period budget constraint of

$$
\mathrm{W}-\mathrm{Ti}=\text { Ciy }+ \text { Aiy }
$$

And a second period budget constraint of

$$
\mathrm{Ai}, \mathrm{y}(1+\mathrm{r})+\mathrm{Ai}-1, \mathrm{o}(1+\mathrm{r})=\mathrm{Ci}, \mathrm{o}+\mathrm{Ai}, \mathrm{o}
$$

Where $\mathrm{Ui}$ is the utility of generation $\mathrm{i}, \mathrm{Ci}$ is the consumption of generation $\mathrm{i}, \mathrm{Ti}$ are taxes and $\mathrm{Ai}$ are the assets of generation $\mathrm{i}$. The subscripts $y$ and o refer to the period when the individual is young and then old respectively. Wage earnings are denoted by $\mathrm{W}$, while the real rate of interest is given by $r$, and $U^{*} i+1$ indicates the utility of the next generation - i.e. of descendents.

In this framework, the consumption and asset demand of the old and young can be written as functions of their net-of-tax bequests, wages and interest. The combination of constraints (i) and (ii) leads to total lifetime budget constraint given by

$$
\mathrm{W}(1+\mathrm{r})+\mathrm{Ai}-1, \mathrm{o}(1+\mathrm{r})=\mathrm{Ci}, \mathrm{y}(1+\mathrm{r})+\mathrm{Ci}, \mathrm{o}+\mathrm{Ai}, \mathrm{o}
$$

This implies that the maximum utility level of an individual is indirectly determined by his wages, his bequest from his parents, and the interest rate. Barro then makes use of equation (iii) to prove his debtneutrality hypothesis by showing that generation $i$ can easily offset the actions of the government by increasing its bequest leaving the net bequest to his heirs unchanged. In doing so, the entire profile of market equlibria is unchanged and the government deficit is neutral. The same results occur if the analysis is extended to taxes being paid by generations further in the future.

Barro's model of debt-neutrality has invited wide-spread criticism both on theoretical and empirical basis while numerous extensions and endorsements of his original model have appeared which attempt to rehabilitate the REH. The proponents of Keynesian tradition believe that changes in stock of government debt and in the timing of taxes will have an impact on the private sector behaviour as well as the economy's equilibrium 
allocations. Their contention is that the individuals suffer from fiscal illusion and as such cannot fully anticipate the future taxes embodied in the currently issued public bonds. Moreover, the possibilities of changes in government stock being accompanied by shifts in government spending cannot be ruled out in the practical world and this would automatically annul the logic underlying REH. The extent of monetisation of the public debt is likely to have its impact on the domestic price level, interest rates and consumption behaviour.

The literature on theoretical and empirical aspects of Ricardian Equivalence Hypothesis (REH) has grown exponentially in the decades of the eighties and nineties. Most of the studies on $\mathrm{REH}$ have their focus on advanced countries specially the US, but these studies have not succeeded in resolving the controversies associated with this important hypothesis.

The main studies which find support for REH are those of Kochin (1974), Barro (1978), Tanner (1979), Seater (1982), Kormendi (198), Aschauer (1985), and Seater and Mariano (1985). These studies find no evidence of there being an increase in consumer sprending resulting from a higher level of government debt. On the other hand, Feldstein (1978, 1979, 1982), Blinder and Deaton (1985), Boskin and Kotlikoff (1985), and Modigliani and Sterling (1986) produce empirical results which contradict the basic logic of REH. Evans (1988) reviews the studies mentioned above and points out that none of these studies derives the consumption function it estimates from a well-specified model that nests both Ricardian equivalence and an alternative in which households regard government debt as net wealth. For example, many of the studies motivate the models that they estimate by appealing to the life cycle model, which does not nest Ricardian equivalence. Still others are based on the permanent-income mode1, which does not nest any alternative to Ricardian equivalence. However he finds Blanchard (1985) as one of the few models in the literature that does nest Ricardian equivalence and such an alternative. Depending on whether a crucial parameter is zero or positive, households have infinite horizons, internalise all future generations, and exhibit Ricardian behaviour; or they have finite horizons, are at least somewhat disconnected from future generations, and exhibit non-Ricardian behaviour.

Evans (1988) examines the basic implications of Blanchard's paper but finds no evidence from the US data for Blanchard's alternative to Ricardian Equivalence. Thus he finds the consumption behaviour of US households in line with the basic logic of REH. 
For developing countries, there is hardly any meaningful study which tests the fundamental postulate of Ricardian Equivalence. Kazmi (1991) is one of the early attempts which empirically examines the validity of Ricardian Equivalence for Pakistan using macroeconomic data for the period 1960-88. This study is followed by Kazmi (1992, 1994 and 1995) which taken together reject the relevance of REH for a developing country like Pakistan.

\section{Part II}

\section{Blanchard-Evans Models}

In this section, the Blanchard (1985) model is outlined as refined and extended by Evans (1988). It would be appropriate therefore to call it the Blanchard-Evans Model and while outlining the model here, only minor changes are made in the overall derivation and system of equations as incorporated in Evans (1988). This is imperative to maintain the consistency of the model.

Evans first discusses the basic assumptions of the Blanchard model namely that households face perfect capital and insurance markets but have finite horizons because a fraction $\mu$ of them dies during such period. Given these assumptions and some assumptions about preferences and the distribution of income and wealth, the aggregate consumption function assumes the form:

$$
C_{t}=\alpha\left[\left(1+R_{t}\right) A_{t}-1+\sum_{i=0}^{o o}(1-\mu)^{i} \beta_{i t} E_{t} W_{t+i}\right]
$$

Where $C_{t}$ is aggregate consumption during period $t, A_{t-1}$ is the stock of assets outstanding at the end of period $t-1, R_{t}$, is the real holding-period yield during period $\mathrm{t}$ on the assets carried over from period $t-1, E_{t}$ is the expectations operator conditional on the information known by households during period $t, W_{t}$, is aggregate disposable wage income during period $t$, $\beta_{0 t}=1$,

$$
\beta_{i t} \equiv \frac{1}{\prod_{j=1}^{i}\left(1+F_{j t}\right)}, i>0
$$


$F_{j t}$, is the forward real interest rate in period $\mathrm{t}$ on bonds that will be issued in period $t+j-1$ and that will mature in period $t+j$, and $\alpha$ and $\mu$ are parameters satisfying $0<\alpha<1$ and $0 \leq \mu<1$. Households treat the term in brackets as wealth, consuming the fraction $\alpha$ of it every period. Wealth equals $A_{t-1}$, the market value of all assets that have been accumulated, plus $W_{t}+R_{t} A_{t-1}$, current disposable income plus $\sum_{i=1}^{\infty}(1-\mu)^{i} \beta_{i t} E_{t} W_{t+i}$, the expected present value of the future disposable wage income that will be received by current households. If $\mu>0$, households discount taxes at a higher rate than they discount future interest income. In other words, one unit of taxes in period $t+i$ has the present value $(1-\mu)^{i} \beta_{i t}$ which is smaller than $\beta_{i t}$ the present value of one unit of interest income.

The aggregate budget constraint is

$$
W_{t}+R A_{t-1}=C_{t}+\Delta A_{t}
$$

Where $\Delta$ is the difference operator. Equation (3) states that aggregate disposable income $W_{t}+R_{t} A_{\mathrm{t}-1}$ can be either consumed or accumulated as assets. It is assumed that the following variant of the expectations theory of the term structure holds:

$$
E R_{t}+A_{t+i-1}=F_{i E} E_{1} A_{t+i-1} .
$$

Using equation (3) to eliminate $W_{t}, W_{t+1}, W_{t+2}$, from equation (1) and substituting from equation (4) results in

$$
C_{t}=\alpha \sum_{i=o}^{o o}(1-\mu)^{i} B_{i} E_{t}\left(C_{t+i}+\mu A_{t+i}\right)
$$

Consumption is therefore increasing in $E_{t} A_{t}, E_{t} A_{t+1}, E_{t} A_{t+2}, \ldots$ unless Ricardian Equivalence holds and $\mu=0$. Consequently, the higher the households expect the future path of the government debt to be, ceteris paribus, and hence the higher are $E_{t} A_{t}, E_{t} A_{t+1} E_{t} A_{t+2} \ldots \ldots$ the more households consume.

Evans then incorporates the common assumption in the consumption literature that real interest rates are constant and equal at every horizon. This assumption implies that for every ${ }_{i}$ and ${ }_{t}$ 


$$
\beta_{i t}=\beta_{i}
$$

Where $\beta$ is parameter satisfying $0<\beta<1$. Substituting equation (6) into equation (5) yields

$$
C t+\alpha \sum_{i=o}^{o o}(1-\mu)^{i} \beta \mathrm{i}^{i} E_{t}\left(C_{t=i}+\mu A_{t=i}\right),
$$

Lagging equation (7) one period, multiplying both members by $1 /(1$ $\mu$ ), subtracting the resulting equation from equation (7) and arranging yields

$$
C_{t}=\left[\frac{1-\alpha}{\beta(1-\mu)}\right] C_{t-1}-\left[\frac{\alpha \mu}{\beta(1-\mu)}\right] A_{t-1}+U_{t}
$$

where

$$
U_{t} \equiv \alpha \sum_{i=0}^{00}(1-\mu)^{i} \beta i\left(E_{t}-E_{t-1}\right)\left(C_{t+i}+\mu A_{t+i}\right)
$$

By construction, $U_{t}$ is uncorrelated with all information available to households in period $t-1$ and hence with $C_{t-1}$ and $A_{t-1}$. Therefore, the ordinary least squares estimator of the coefficient on $A_{t-1}$ has a zero probability limit if Ricardian equivalence holds and a negative probability limit if Blanchard's alternative holds.

Taking logarithms of both members of equation (5), using equation (2)- to eliminate $\beta_{i t}$, and rearranging yields

$$
\begin{aligned}
& \ln C_{t}=\ln \alpha+\ln \left(C_{t}+\mu A_{t}\right) \\
& +\ln E_{t}\left[1+\sum_{i=l}^{o o}(1-\mu)^{i} \exp \left(\sum_{j=l}^{i} x_{i t}\right)\right],
\end{aligned}
$$

Where $\chi_{i t} \equiv \Delta \ln \left(C_{t+1}+\mu A_{t+i}\right)-f_{\text {it }}$ and $f_{i t} \equiv \ln \left(1+F_{i t}\right)$. Evans then shows that equation (10) can be approximated as

$$
\Delta \ln C_{t}-r_{t}=\kappa-\left(\frac{1-\gamma}{\gamma}\right) \mu\left(\frac{A_{t-1}}{C_{t-1}}\right)+u t
$$


Where $r_{t} \equiv \ln \left(1+R_{t}\right), \gamma \equiv(1-\mu) \exp (\bar{x}, \bar{x}$ is the unconditional mean of $x_{1 t}, k \equiv \bar{x}-[(1-\gamma) / \gamma] \ln [\alpha /(1-\gamma)]$, and

$$
\begin{aligned}
& u t \equiv \sum_{i=0}^{o o} \gamma^{i}\left(E_{t}-E_{t-l}\right) \Delta \ln \left(C_{t+l}+\mu A_{t+i}\right) \\
& -\left(1-E_{t}-l\right) r_{t}-\sum_{i=1}^{o o} \gamma_{i i}\left(l-E_{t-1}\right) f_{i t} \\
& -\left(E_{t}-r_{t}-f_{t t-t}\right)-\sum_{i=l}^{o o} \gamma_{i}^{i}\left(E_{t-1} f_{i t}-f_{i+l t-t}\right),
\end{aligned}
$$

By construction, $\sum_{\mathrm{i}=0} \gamma^{\mathrm{i}}\left(\mathrm{E}_{\mathrm{t}}-\mathrm{E}_{\mathrm{t}-1}\right) \Delta \ln \left(\mathrm{C}_{\mathrm{t}+\mathrm{i}}+\mu \mathrm{A}_{\mathrm{t}+\mathrm{i}}\right),\left(1-\mathrm{E}_{\mathrm{t}-1}\right) \mathrm{r}_{\mathrm{t},}$ and $\sum_{\mathrm{i}=1}$ $\gamma^{\mathrm{i}}\left(1-\mathrm{E}_{\mathrm{t}-1}\right) f_{\mathrm{it}}$ are uncorrelated with all information available to households in period $\mathrm{t}-1$. It is assumed that the term premia $\mathrm{E}_{\mathrm{t}-1} \mathrm{r}_{\mathrm{t}-} f_{1 \mathrm{t}-1}, \mathrm{E}_{\mathrm{t}-1} f_{1 \mathrm{t}}-f_{2 \mathrm{t}}-_{1}, \mathrm{E}_{\mathrm{t}-1} f_{2 \mathrm{t}-}$ $f 3_{t-1}, \ldots$. contribute negligibly to the variance of $u_{t}$. This will be true if the expectations theory of the term structure holds. It will also be approximately true if the expectational errors in equation (12) are much more variable then the term premia because, say, households cannot accurately predict the future evolution of $\mathrm{rt}, f 1 \mathrm{t}, f 2 \mathrm{t}, f 3 \mathrm{t}, \ldots \ldots$ or $\Delta \ln \left(\mathrm{C}_{\mathrm{t}}=\mu \mathrm{A}_{\mathrm{t}}\right)$. In either case $\mu_{\mathrm{t}}$ can be taken to be serially uncorrelated and uncorrelated with $A_{t-1} / C_{t-1}$ as well. Therefore, the ordinary least squares estimator of the coefficient on $A_{t-}$ ${ }_{1} / \mathrm{C}_{\mathrm{t}-1}$ has a zero probability limit if Ricardian equivalence holds and negative probability limit if Blanchard's alternative holds.

Evans then suggests that ordinary least squares be used to estimate a regression of the form

$$
\begin{aligned}
& C_{t}=\pi_{0}+\sum_{i=1}^{n} \pi_{c i} C_{t-i} \sum_{i=0}^{n} \pi_{d i} d_{t-i} \sum_{i=0}^{n} \pi_{k i} \Delta \ln K_{t-i} \\
& +\sum_{i=0}^{n} \pi_{r i} r_{t-i}+\sum_{i=0}^{n} \pi_{g i} g_{t-i}+\hat{\mathcal{V}}_{t,}
\end{aligned}
$$

Where $D_{t}$ is the stock of government debt, $K_{t} \equiv A_{t}-D_{t}, c_{t} \equiv C_{t} / K_{t}$, $d_{t} \equiv D_{t} / K_{t}, g_{t}$ is the ratio of government purchases to $K_{t}$, the $\pi$ 's are regression coefficients, $n$ is a nonnegative integer, and the $\hat{v}^{\prime} s$ are the residuals from the regression. Let $l_{t}$ and $X_{t}$ be the set of information used by households in forming expectations at time $t$ and the set of regressors 
used in equation (13), respectively. It can be shown that if $X_{t}$ is a subset of $l_{t}$, then

$$
p \lim \hat{v}_{t}=\mu\left(\frac{\alpha}{l-\alpha}\right) \sum_{i=1}^{o o} \phi^{i}\left(E d_{t+i}\left|I_{t}-E d_{t+i}\right| X_{t}\right)+e_{t}
$$

In equation (14), the parameter $\phi$ satisfies $0<\phi<1$, and the error term $e_{t}$ incorporates all effects that do not result from revised expectations of the future path of $d_{t}$ and that cannot be predicted using $X_{t}$.

Now let us consider an intervention that, ceteris paribus, leads households to predict a higher (lower) future path for $d_{t}$ than the one that can be predicted using $X_{t}$ alone. Because the ceteris paribus restriction requires $e_{t}$ to be zero, equation (14) implies that plim $v_{t}$ must be positive (negative) if $\mu>0$ and must be zero if $\mu=0$.

Simplifying equation (8) and (11), Evans establishes that the error term $\bar{U}_{t}$ in the equation

$$
\bar{C} t=\delta \bar{C}_{t-1}+\theta A_{t+1}+\bar{U} t
$$

is serially correlated and correlated with $\bar{U}_{t-1}$ and $A_{t-1}$ as well. Similarly, the error term $\bar{u}_{t}$ in the equation

$$
\Delta \ln \bar{C}_{t}-\bar{r}_{t}=\varphi+\omega\left(\frac{A_{t-1}}{\bar{C}_{t-1}}\right)+\bar{u}_{t}
$$

is serially correlated and correlated with $A_{t-1} / \bar{C}_{t-1}$. In equations $(15)$ and (16), $\delta, \theta, \psi$, and $\varpi$ are parameters.

Evans then shows that under the null hypothesis of Ricardian Equivalence $\bar{U}_{t}$ is a first-order moving average, $\bar{C}_{t-2}$ and $A_{t-2}$ are uncorrelated with $\bar{U} t$, and $\theta=0$. In contrast, if Blanchard's alternative hypothesis holds, $\theta<$ o. In other words, the Ricardian equivalence can be tested against Blanchard's alternative by examining the estimate obtained for $\theta$.

Similarly, the estimated co-efficient of $A_{t-1} / C_{t-1}$ in equation (16) would determine whether consumers are Ricardinan or otherwise. If the value of the co-efficient is zero, the Ricardian Equivalence Hypotheses is validated and if its value is negative, Blanchard's alternative would hold and 
consumers would be classified as non-Ricardian. If the co-efficient turns out to be positive, consumer behaviour would be considered to follow the middle path between the two extremes.

\section{Part-III}

\section{Testing of Ricardian Equivalence for Pakistan}

To recapitulate, the theoretical model developed by Blanchard has shown that the planning horizon of the government and individuals recognised the possibility of death or dynastic extinction, so that the individual discount rate would be higher than that of the government leading to current taxation being treated differently from future taxation. Since this model nests both Ricardian and Non-Ricardian alternatives, it is useful for modelling deviations from strict equivalences. An extension and empirical testing of Blanchard's model has been attempted by Evans (1988) with results based on quarterly post-war U.S. data generally consistent with the Ricardian Equivalence Hypothesis. The following two equations are estimated by Evans to test REH:

$$
\begin{aligned}
& \mathrm{Ct}=\mathrm{aoCt}-1+\mathrm{a} 1 \mathrm{At}+\mathrm{et} \\
& \mathrm{D} \ln \mathrm{Ct}-1-\mathrm{rt}=\mathrm{b} 0+\mathrm{b} 1((\mathrm{At}-1) /(\mathrm{ct}-1))+\mathrm{vt}
\end{aligned}
$$

Where Ct and Ct-1 are current and lagged value of the per capita real consumption, At- 1 is the market value of assets lagged by one period, rt $=\ln (1+\mathrm{Rt})$, Rt being the short term nominal rate of interest, et and vt are error terms and $\mathrm{a} 0$, a1, b0 and $\mathrm{b} 1$ are parameters.

In the Blanchard model, al and b1 are functions of an important parameter, $\mu$ defined as the rate at which households "die" and are replaced by households completely unconnected with the old ones. The full equations of the Blanchard-Evans model are:

$$
\begin{aligned}
& \mathrm{Ct}=(1-\mathrm{a}) /(\mathrm{b}(1-\mu)) \mathrm{Ct}-1-(\mathrm{a} \mu) / \mathrm{b}(1-\mu) \mathrm{At}-1+\mathrm{ut} \\
& \mathrm{D} 1 \mathrm{Ct}-\mathrm{rt}=\mathrm{ko}-(1-\mathrm{k} 1) /(\mathrm{k} 1) \mu(\mathrm{At}-1) /(\mathrm{Ct}-1)+\mathrm{vt}
\end{aligned}
$$

The magnitude of $\mu$ is thus critical in determining whether consumers behave according to Ricardian Equivalence or not. If $\mu$ is zero, households act as if they are infinitely lived or they fully care for the welfare of the future generations through intergenerational transfers. If $\mu$ is somewhat above zero, households behaviour reflects long but finite horizons 
indicating that they are somewhat disconnected from their descendants. According to Blanchard, if $\mu$ is nearly one, households act as if "they are disconnected from their own biological selves. Therefore, $\mu$ measures not only the finiteness of life and the disconnectedness of generations but also the myopia with which households foresee future taxes. In addition, $\mu$ serves as a metaphor for how imperfectly human capital markets operate."

The crucial test of Blanchard-Evans model is that if al and b1 turn out to be zero, the consumers belong to the Barro-Ricardo category. However, if they are negative and significant, they would be Non-Ricardian. If al and b1 are positive, the consumers' behaviour could be considered as a middle path between the two extremes of pure Ricardian and Non-Ricardian positions.

The OLS estimates of consumption function for Pakistan based on the Blanchard-Evans models using different definitions of the wealth variable are given in Table I and Table II. In equation 1 of Table 1 , the wealth variable which is defined so as to include public debt, money supply (M2) and capital stock, has a co-efficient equal to 0.034 which is not significant at the $5 \%$ level, implying that consumers are strictly Ricardian. When wealth (A') is defined in a more restricted sense such that it includes public debt and money supply, then the regression co-efficient of $A^{\prime}$ assumes a positive value which is significant at the traditional 5\% level, as is evident from equation 2. When wealth is defined in terms of money supply (M2) only, the co-efficient of the lagged variable is again positive and significant (equation 3). Therefore, the results of the last two equations support neither the Ricardian nor the non-Ricardian position. In fact, the consumers follow the middle path between the two diametrically opposed situations.

In Table II, results of equation (ii) of Blanchard-Evans models are presented. In this case, the dependent variable is the difference between growth rate of real per capita consumption and the term rt $=\log (1+\mathrm{Rt})$ where Rt is the short run nominal interest rate, while the ratio of wealth stock to the consumption per capita lagged by one year is the independent variable. In equation 1 of Table II, we use the wealth definition as used in equation 1 of Table I and find the co-efficient of At-1/(Cp)t-1 to be positive and significant at the $5 \%$ level, which implies that RE proposition does not hold. The reasonable value of R2 (0.426), D.W equal to 1.608 and Fstatistics equal to 21.045 indicate that the fit of the equation is quite good. In equation 2, wealth is defined to consist of debt and M2 only, giving parameter estimates of 0.016 which is not significant at the $5 \%$ level, an indication that RE holds. However, the low value of R2, DW and F-statistics of the equation do not permit much confidence to be placed in the 
parameter estimates. Similar conclusions can be drawn from equation 3, where wealth is defined to include only M2 and the values of R2, D.W and F statistics are too low to provide any reasonable level of confidence in the results of the equation. In short, virtually all variants of the Blanchard-Evans model as applied to Pakistan data reject REH.

The above results indicate that the Ricardian Equivalence Hypothesis is an extreme and oversimplified generalisation and a very rough approximation of consumer behaviour which takes into account the public debt and the bonds issued to realise that debt. As part of intertemporal allocation of resources between consumption and savings, therefore, further research is required to test the validity of this important hypothesis of public finance, especially for developing countries like Pakistan.

Similar conclusions about consumer behaviour have been derived in Kazmi (1995) a study about tax-discounting in Pakistan, which suggests that consumer response to fiscal policy reflects neither the extreme Barro like rational anticipation of future tax liabilities nor extreme type of fiscal myopia. It follows a middle path between the two extremes. 
Aqdas Ali Kazmi 87

Table-1: Tests of Ricardian Equivalence

Dep. Var: $\mathrm{CP}=$ Real Per Capita Private Consumption

\begin{tabular}{cccc}
\hline & OLS & OLS & OLS \\
\hline C & -36.646 & 23.894 & 24.794 \\
& $(-0.844)$ & $(1.581)$ & $(1.769)$ \\
(CP)t-1 & 0982 & 0.845 & 0.806 \\
& $(17.684)$ & $(10.629)$ & $(10.042)$ \\
At-1 & 0.034 & - & - \\
& $(0.910)$ & & \\
A't-1 & - & 0.220 & - \\
& & $(2.399)$ & \\
A”t-1 & - & - & 0.374 \\
& & & $(2.866)$ \\
-2 & 0.983 & 0.986 & 0.987 \\
R & 1.570 & 1.4178 & 1.465 \\
D.W & 596.680 & 942.966 & 1019.290 \\
F & 5904.700 & 4821.170 & 4464.550 \\
SSR & &
\end{tabular}

\section{Definitions:}

A: Wealth variable which includes public debt (privately held), M2 and capital stock $(\mathrm{K})$

A': Wealth variable which includes public debt (privately held) and M2

A": Wealth variable which includes M2 only 
The Labore Journal of Economics, Vol.6, No.1

Table-2: Tests of Ricardian Equivalence

DEP. VAR: Dln Cp - rt

\begin{tabular}{cccc}
\hline & OLS & OLS & OLS \\
\hline C & -0.225 & -0.045 & -0.011 \\
& $(-5.377)$ & $(-0.657)$ & $(-0.169)$ \\
At-1/(Cp)t-1 & 0.052 & - & - \\
A't-1/(Cp)t-1 & $(4.587)$ & & - \\
A"t-1/(Cp)t-1 & - & 0.016 & \\
& - & $0.144)$ & -0.054 \\
-2 & & - & $(-0.377)$ \\
R & 0.426 & -0.038 & -0.033 \\
D.W & 1.608 & 1.119 & 1.229 \\
F & 21.045 & 0.21 & 0.142 \\
SSR & 0.27 & 0.049 & 0.049 \\
\hline
\end{tabular}

\section{Definitions:}

$A=\quad$ Wealth variable which includes debt, M2 and capital stock.

$\mathrm{A}^{\prime}=\quad$ Wealth variable which includes debt and M2.

$A "=\quad$ Wealth variable which includes M2 only.

DlnCp $=$ Annual growth rate of consumption (real per capita).

$r t=\quad \log (1+R t)$

$\mathrm{Rt}=\quad$ Short run nominal interest rates. 
Aqdas Ali Kazmi 89

\section{References}

Aschauer, David A. Fiscal Policy and Aggregate Demand”, American Economic Review 75 (March 1985): 117-28

Baily, M.J., 1971 National Income and the Price Level. $2^{\text {nd }}$ Edition, New York, McGraw Hill.

Barro, Robert J. “Are Government Bonds Net Wealth?" J.P.E. 82 (November/December 1974): 1095-1117.

------- The Impact of Social Security on Private Saving: Evidence from the US. Time Series. Washington: American Enterprise Inst., 1978.

Blanchard, Oliver J. "Debt, Deficits, and Finite Horizons.” J.P.E. 93 (April 1985): $223-47$.

Blinder, Alan, S., and Deaton, Angus. "The Time Series Consumption Function Revisited.” Brookings Papers Econ. Activity, no. 2 (185), pp. 465-511.

Boskin, Michae1 J., and Kotlikoff, Laurence J. "Public Debt and United State Saving: A New Test of the Neutrality Hypothesis." CarnegieRochester Conf. Ser. Public Policy 23 (Autmn1985): 55-86.

Evans, Pau1. "Do Large Deficits Produce High Interest Rates?" American Economic Review 75 (March 1985): 68-87.

----- "Is the Dollar High because of Large Budget Deficits?" J. Monetary Economics 18 (November 1986): 227-49.

----- "Do Budget Deficit Raise Nominal Interest Rates? Evidence from Six Countries.” Journal of Monetary Economics 20 (September 1987): 281-300. (a)

------ "Interest Rates and Expected Future Budget Deficits in the United States.” J.P.E. 95 (February 1987): 34-58 (b)

Feldstein, Martin S., 1978 "Reply." In The Impact of Social Security on Private Savings: Evidence from the U.S. Time Series, by Robert J. Barro. Washington: American Enterprise Inst. 
"The Effect of Social Secrity on Private Savings: The Time Series Evidence.” Working Paper no. 314. Cambridge, Mass.: NBER, 1979.

------ "Government Deficits and Aggregate Demand." J. Monetary Econ. 9 (January 19832): 1-20.

Ha1l, Robert E. "Stochastic Implications of the Life Cyucle -Permanent Income Hypothesis: Theory and evidence." J.P.E. 86 (December 1978): 971-87.

Hansen, Lars Peter. "Large Sample Properties of Generalized Method of Moments Estimators.” Econometrica 50 (July 1982): 1029-54.

Judd, Kennth. "Debt and Distortionary taxation in a Simple Perfect Foresight Mode1.” J. Monetary Econ. 20 (July 1987): 51-72.

Kazmi, Aqdas Ali (1991). Savings, Consumption and Ricardian Equivalence, A Macroeconometric Analysis of Pakistan: 1960-88. Ph.D. Dissertation, Boston University.

--------(1992). Ricardian Equivalence; Some Macroeconometric Tests for Pakistan. The Pakistan Development Review 31:4.

-(1994). Private Consumption, Government Spending and Debt Neutrality: Resolving Kormendi-Feldstein-Modigliani Controversy. The Pakistan Development Review 33:4.

------(1995). Econometric Estimation of Tax Discounting in Pakistan. The Pakistan Development Review 34:4.

Kochin Levis A. (August 1974) "Are Future Taxes Anticipated by Consumers? Comment.” J. Monewy. Credit and Banking 6: 385-94.

Kormendi, Roger C. "Government Debt, Government Spending, and Private Sector Behaviour.” American Economic Review 73 (December 1983): 994-1010.

Modigliani, Franco, and Sterling, Arlie. "Government Debt, Government Spending Private Sector Behaviour: Comment.” A.E.R. 76 (December 1986): 1168-79.

Patinkin, D., Money, Interest and Prices, 1965. $2^{\text {nd }}$ Edition, New York, Harper and Row. 
Aqdas Ali Kazmi 91

Seater, John J. “Are Future Taxes Discounted?" J. Money, Credit and Banking, 14 (August 1982): 376-89.

and Mariano, Roberto S. "New Tests of the Life Cycle and Tax Discounting Hypothesis” J. Monetary Econ. 15 (March 1985): 195215 .

Sraffa, Piero., 1951 The Works and Correspondence of David Ricardo, Vol. 4, Pamphlets and Papers, 1815-1823. Cambridge: Cambridge Univ. Press.

Tanner, J. Ernest. "An Empirical Investigation of Tax Discounting: A comment.” Money, Credit and Banking 11 (May 1979): 214-18. 